\title{
Short Note \\ The Rupture Mode of the Shallow Large-Slip Surge of the Tohoku-Oki Earthquake
}

\author{
by Christopher H. Scholz
}

\begin{abstract}
The remarkable feature of the $M_{\mathrm{w}} 9.1$ Tohoku-Oki earthquake of 2011 was a late, shallow, surge that propagated from about $12 \mathrm{~km}$ depth all the way to the trench. This surge had very large slip and was depleted in high-frequency radiation. It was followed by normal faulting in the outer wedge; this requires that the postsurge basal shear stress be close to zero. Explanations for the surge propagating through the velocity-strengthening region by a thermal weakening mechanism fail to produce the near-total stress drop required by the postseismic extension. The surge propagated in a region of material contrast across the plate interface. The combination of a strong nucleation pulse from down dip, velocity strengthening, and the bimaterial effect satisfies the conditions for wrinkle pulse propagation. A wrinkle pulse rupture mode can produce an instability by overcoming velocity strengthening with the normal stress reduction produced by the bimaterial effect. It also leads to total stress drop, satisfying the extension constraint and explaining the prodigious slip amplitude of the surge. Because the surfaces are detached in wrinkle pulse mode, asperity contact is reduced, which explains the dearth of high-frequency radiation during the surge. This behavior appears to be a common feature of many of the greatest subduction earthquakes.
\end{abstract}

\section{Introduction}

The $M_{\mathrm{w}} 9.0$ Tohoku-Oki earthquake of 2011 was remarkable because of a late, shallow, large-amplitude slip surge that ruptured to the trench. The earthquake began as a fairly typical subduction megathrust event. Initiating at a depth of about $20 \mathrm{~km}$ and some $100 \mathrm{~km}$ landward from the trench, it first propagated primarily down dip. About $50 \mathrm{~s}$ after initiation, a large-slip surge began at about $60 \mathrm{~km}$ from the trench at a depth of about $12 \mathrm{~km}$ and propagated up dip all the way to the trench (Fujiwara et al., 2011; Ide et al., 2011). It had previously been believed that megathrust earthquakes could not propagate to shallow depths close to the trench, being inhibited by the presence there of velocity-strengthening materials such as clays (Hyndman and Wang, 1993; Scholz, 1998; Saffer and Marone, 2003). The shallow-slip surge was also notable for the paucity of short-period radiation, suggesting smooth and uninhibited slip, and an unprecedented slip magnitude of over $50 \mathrm{~m}$, suggesting a very high, perhaps total, stress drop (Ide et al., 2011; Simons et al., 2011). The shallow large-slip surge was largely responsible for the great size of the tsunami that the earthquake produced. Tsunami records indicate that earthquakes like that of 2011 have occurred off Tohoku previously but at very long intervals, the penultimate one having been the Jogan earthquake of 869 (Minoura et al., 2001). The more typical plate boundary ruptures in that area consist of $M_{\mathrm{w}} 7.5-8.0$ earthquakes that recur at 30- to 50-year intervals in the deeper seismogenic region of high seismic coupling (Hashimoto et al., 2009; Loveless and Meade, 2010). Those earthquakes account for only about half the accumulating seismic flux rate (Scholz and Campos, 2012) and do not spawn shallow-slip surges like the one in the 2011 earthquake.

Noda and Lapusta (2013) developed a model that satisfactorily explained several of the features of the shallow-slip surge. They proposed a model composed of two sections. Section A, representing the deeper region, is strong (friction coefficient $\mu=0.7$ ), has velocity weakening, and is not prone to thermal pressurization weakening. The adjacent section B, representing the shallow up-dip region, has moderate strength $(\mu=0.4)$, is velocity strengthening, and is prone to thermal pressurization weakening. When rupture from section A impinges upon section $B$, thermal pressurization of the pore fluid can result in weakening that dominates the velocity strengthening, thus resulting in an instability that propagates through that section. When this happens, the result looks very much like the Tohoku-Oki earthquake, with much greater slip in the shallow than the deeper segment. This model also reproduced another important feature: in many cycles rupture of the deeper section did not extend into the shallow section, which 


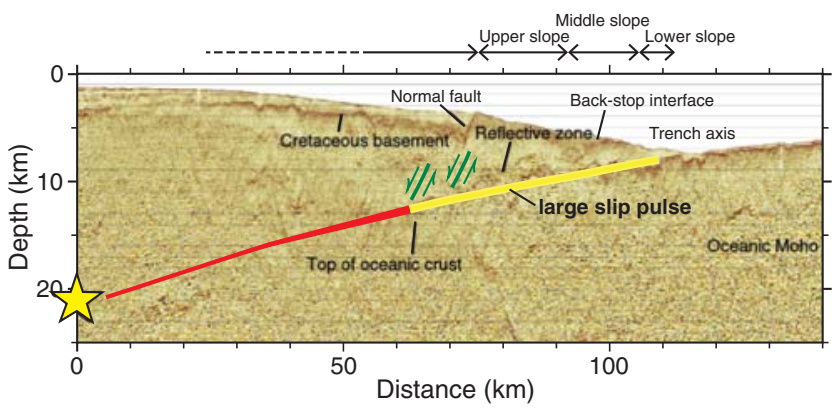

Figure 1. Cross section of the outer rupture zone of the 2011 Tohoku-Oki earthquake. Star, earthquake hypocenter; red curve, rupture zone of moderate amplitude section with short-period radiation; yellow curve, rupture zone of large-slip surge with no shortperiod radiation; and green symbols, large normal-faulting aftershocks. Background structure obtained from Kodaira et al. (2012), with permission.

slipped stably in the interseismic period. This is required to explain the rarity of shallow surges.

\section{The Extension Constraint}

Postearthquake surveys revealed a prominent landwarddipping normal fault with a large surface offset about $40 \mathrm{~km}$ landward from the trench. There was evidence for this fault having been reactivated by the earthquake (Kodaira et al., 2012; Tsuji et al., 2013). There was also a series of strong normal-faulting aftershocks in the upper plate about $60 \mathrm{~km}$ from the trench near the initiation point of the shallow-slip surge (Obana et al., 2013). This evidence for extension in the outer part of the accretionary prism, shown in Figure 1, provides strong constraints on the postseismic basal shear stress within the region of the large shallow-slip surge. Cubas et al. (2013) applied the Coulomb wedge model to this problem and concluded that to account for the extension the effective basal friction following the earthquake must have been $\mu_{b}^{\text {eff }} \leq 0.003$. Assuming that the Hubbert-Rubey parameter they found for the interior of the outer wedge, $\lambda=0.8$, applies to the base, this implies a basal friction coefficient there of $\mu_{b} \leq 0.015$. The average shear stress over this section of the thrust following the earthquake must therefore have been less than $0.5 \mathrm{MPa}$, a value not significantly different from zero.

In 2012, the Japan Trench Fast Drilling (JFAST) project drilled a series of closely spaced boreholes through the Tohoku-Oki rupture zone near the trench. Temperature measurements near the base of the borehole showed a very small thermal signature (Fulton et al., 2013), indicating shear stress of $\sim 0.5 \mathrm{MPa}$ operating during seismic slip. From a study of borehole breakouts in the JFAST borehole, Lin et al. (2013) concluded that the residual shear stress on the thrust interface must be $\leq 0.3 \mathrm{MPa}$. Both findings are consistent with the Cubas et al. (2013) analysis.

These results provide very strong constraints on any possible sliding mechanism that may have operated during the shallow-slip surge. In the Noda and Lapusta (2013) model, the shear stress that operated during sliding of segment B

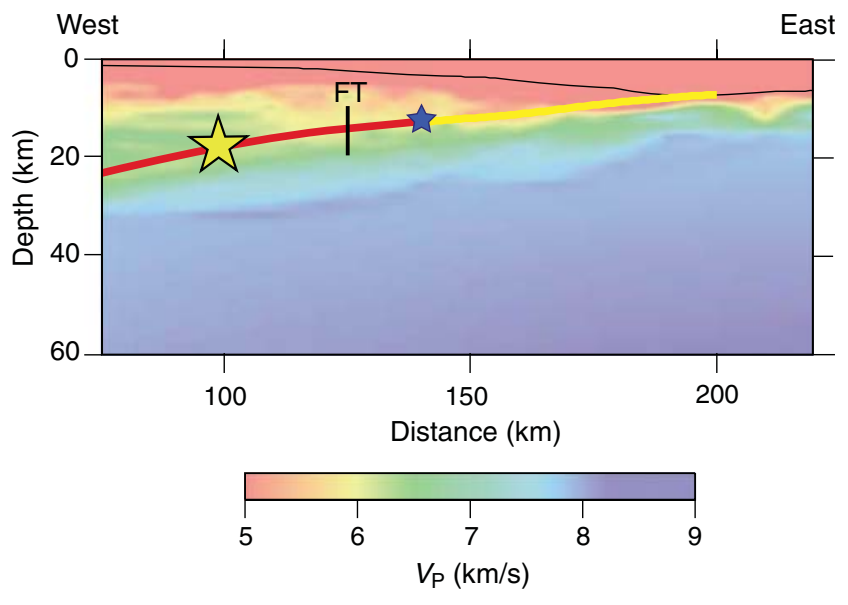

Figure 2. Velocity structure of Tohoku-Oki segment of the Japan subduction zone (from Yamamoto et al., 2011). FT is the trenchward extent of the seismogenic zone, based on the rupture zone of the $1981 M_{\mathrm{w}} 7.1$ earthquake (Ito et al., 2005). Yellow star, earthquake hypocenter and blue star, estimated beginning of the shallow surge, based on Ide et al. (2011).

was $\sim 10 \mathrm{MPa}$, implying that $\mu_{b}^{\mathrm{eff}}=0.10$. According to $\mathrm{Cu}-$ bas et al., this level of friction would produce thrusting in the outer wedge, rather than extension. Because the weakening mechanism that Noda and Lapusta proposed requires frictional work to generate the heat to produce the pressurization of the pore fluid, it contains a negative feedback that prevents the shear stress from dropping to a very low value. Faulkner et al. (2011) conducted friction experiments on various clay fault gouges at coseismic slip velocities. Their wet, fast, experiments produced the same thermal pressurization effect that operated in the Noda and Lapusta model. Those experiments showed that $\mu^{\text {eff }}$ never fell below 0.1 , demonstrating the negative feedback effect. This same restriction exists for all the weakening mechanisms at high sliding velocity discussed by Di Toro et al. (2006), which they showed were all thermally induced. The basal friction obtained by Cubas et al. is too low $(0.015)$ to represent the real friction coefficient of any known geological material under any conditions. This leads us to abandon the whole concept of thermal weakening of friction as an explanation for the shallow surge.

\section{The Bimaterial Effect}

One of the characteristics of subduction zones is that the plate interface separates regions of contrasting elastic constants. At shallow depths, the seismic velocity of the upper plate is usually less than the lower plate, and this contrast increases with decreasing depth. This feature is shown for the region of the Tohoku-Oki earthquake in Figure 2.

Weertman (1980) showed analytically that instability could arise in mode II sliding on the interface between dissimilar materials characterized by Coulomb friction with no weakening. This arises because when rupture propagates in the slip direction of the more compliant (slow) material, dilatation occurs normal to the interface that reduces the 
normal stress. This bimaterial effect grows rapidly with slip, leading to detachment of the surfaces whereupon rupture propagates along the interface like a wrinkle in a carpet. This wrinkle pulse propagates steadily at the generalized Rayleigh-wave velocity. Propagation in the opposite direction cannot occur by this mode because the interface normal displacement is compression rather than dilation.

Weertman's theoretical prediction was verified by experiments with foam rubber (Anooshehpoor and Brune, 1999) and with numerical simulations (Andrews and Ben-Zion, 1997). At that time, the interest in this rupture mode was in explaining the so-called heat flow paradox of the San Andreas fault.

The shallow surge of the Tohoku-Oki earthquake is a potential candidate for the wrinkle pulse rupture mode. The point FT in Figure 2 is the most trenchward extent of interface seismicity (the rupture zone of the $1981 M_{\mathrm{w}} 7.1$ earthquake) and therefore marks the likely trenchward limit of the velocity-weakening zone (Ito et al., 2005). The small blue star indicates the approximate initiation point of the shallow surge (the exact point of initiation of the surge has not been established-it may lie much closer to point FT). The surge initiation point thus lies within the velocity-strengthening zone and also within the region with contrasting elastic constants across the plate interface. The surge was primarily a mode II rupture front (Ide et al., 2011) propagating in the favored direction for the wrinkle pulse mode and also in a direction of decreasing normal stress and increasing velocity contrast, both of which are increasingly favorable for wrinkle pulse formation.

Weertman's assumption of fixed friction is not relevant to earthquakes in the usual sense because they require weakening friction of some sort (either velocity or slip weakening) for their instability. Numerical modeling employing strong slip weakening showed that the wrinkle pulse was suppressed under those conditions and appeared only as a small-scale part of the dominant crack mode solution (Harris and Day, 1997, 2005). This led Andrews and Harris (2005) to argue that the wrinkle pulse rupture mode is not important in earthquake dynamics, which led to further debate (Andrews and Harris, 2006; Ben-Zion, 2006).

In summarizing their reasons why the wrinkle pulse does not apply to earthquakes under the usual friction weakening conditions, Andrews and Harris (2006) made two statements, both with reference to the initial values of the shear and normal stress on the interface $\tau_{0}$ and $\sigma_{0}$. The first was: "A unilaterally propagating wrinkle-like slip pulse can exist only if friction is larger than $\tau_{0} / \sigma_{0}$, subject to the effects of heterogeneity and dissipation." This does seem to eliminate any cases with weakening friction. But in the case of the surge, we are dealing with a rupture propagating from a velocity-weakening region impinging on a velocity-strengthening region, thus producing a strong nucleation pulse that forces slip in the velocitystrengthening region. In this case, the $>\tau_{0} / \sigma_{0}$ condition will always be met because initially friction will increase because of velocity strengthening and then $\sigma$ will fall because of the bimaterial effect. Their second statement was: "If friction drops below $\tau_{0} / \sigma_{0}$ by any mechanism, such as flash heating or thermal pressurization, bilateral [crack] propagation will result." These or similar mechanisms will not occur in this case, because thermal weakening affects scale with frictional work $\mu \sigma u$ and requires finite slip $u$ to develop, whereas $\sigma \rightarrow 0$ at small $u$ due to the bimaterial effect, thus suppressing such thermal effects.

Therefore, the conditions for wrinkle pulse propagation are met by the shallow surge. Instability arises because the reduction of normal stress by the bimaterial effect overcomes velocity strengthening to produce a stress drop. This explains why the surge could propagate in a velocity-strengthening region while at the same time resulting in a final shear stress near zero, which satisfies the extension constraint and explains the very large displacements. If we think that the short-period pulses of radiation within large earthquakes are due to asperities colliding within the rupture then it is easy to see why a detached wrinkle pulse would be depleted in such radiation (this is similar to the lift-up explanation for the lack of short-period radiation in the northern section of the Chi-Chi earthquake [Ma et al., 2003]).

We still need to explain why the shallow surge off Tohoku is so rare. In an experimental study of wrinkle pulse propagation on a bimaterial interface, Lykotrafitis and Rosakis (2006) found there was threshold level of nucleation pulse strength required to initiate a wrinkle pulse. In Figure 3, the rupture areas of the first, strong short-period radiation part of the 2011 earthquake and that of the late, large-slip part are shown. They are compared with the rupture areas of earlier earthquakes in the Tohoku-Oki region (Koper et al., 2011; Tajima et al., 2013). Rupture zones of earthquakes prior to 2011 indicate that seismic coupling in this area is quite heterogeneous, with frequent earthquakes such as the $M_{\mathrm{w}}<8$ Miyagi-Oki and Fukushima-Oki type confined to rupturing local maxima in seismic coupling. On rare occasions, those coupling peaks become close enough in phase in the seismic cycle that they all rupture together, as they did in 2011. The individual events do not provide a large enough nucleation pulse to spawn a wrinkle pulse in the shallow region, which can only be initiated when the triggering rupture at depth is very large, as in 2011.

A goal of the JFAST borehole was to find out more about the mechanism of slip in the earthquake. Chester et al. (2013) identified a thin layer in the JFAST core of scaly clay that they identified as the locus of major slip. However, indications of rapid seismic slip in the form of depleted alkenones (Rabinowitz et al., 2013) were found at several horizons above and below the scaly layer but not at the scaly clay layer. This suggests that over the approximately $3 \mathrm{~km}$ of total slip recorded in the JFAST boreholes, seismic slip has occurred on several discrete faults distributed over a $30 \mathrm{~m}$ thick interval. The scaly layer does not seem to be the locus of seismic slip but is probably the site of stable sliding in the interseismic period. The coseismic slip in the surge, at most about $50 \mathrm{~m}$, accounts for only about half or less of the plate motion since the Jogan earthquake, with stable interseismic slip required to supply the remainder. 


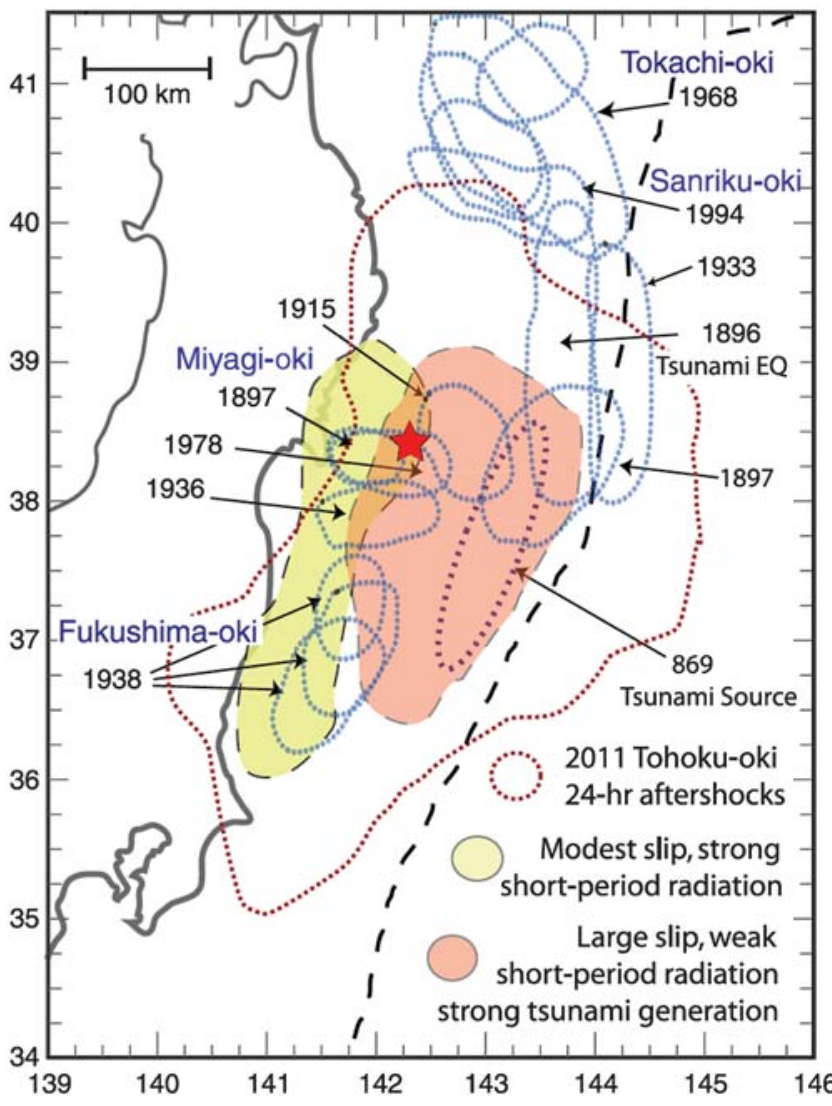

Figure 3. The rupture areas of the modest slip, strong shortperiod radiation part of the Tohoku-Oki earthquake, and the shallow surge (large slip, weak short-period radiation) part. The rupture zones of the historic large subduction earthquakes in this region are also shown (from Koper et al., 2011).

In a wrinkle pulse, most of the slip occurs during tractionfree conditions and so would not produce any shear heating. However, experiments (Lykotrafitis and Rosakis, 2006) show that during the early stage of slip prior to dilation, compression is generated across the slip interface. Therefore, a thermal pulse will be generated by the passage of a wrinkle pulse, the amount being from a shear stress larger than expected working through a displacement that is a small fraction of the total. One of the hot spots found by Rabinowitz et al. (2013) was at the top of the chert layer, which marks the top of the velocity contrast between the upper and lower plates and hence is the most likely place for a wrinkle pulse to be localized. In the chert just below this point was a meter wide chaotically fractured zone. The passage of a wrinkle pulse would be likely to produce a rubble zone due to collapse of fragments from the roof of the opening. It is not, however, known if that brecciation was of natural causes or induced by drilling $(H$. Savage, personal comm., 2014), nor is it known which of the hot spots corresponds to the 2011 rupture. In any case, considering the scale of the surge, we should not expect the wrinkle pulse to be so tightly localized to the velocity contrast interface along the entirety of its rupture length.

\section{Discussion}

As shown in Figure 3, the Tohoku-Oki earthquake was composed of two easily distinguished parts, an early part characterized by relatively modest slip and strong shortperiod radiation and a late part with large slip and weak short-period radiation. The early part was typical of ordinary megathrust earthquakes. The late part, the shallow surge, occurred on the shallow part of the subduction interface in which velocity-strengthening friction ordinarily precludes earthquake propagation, both in this region and elsewhere. Not only did the shallow surge produce prodigious slip, but it also resulted in normal-faulting aftershocks that require it to have undergone a total stress drop. Explanations of the shallow surge that involve thermal weakening mechanisms to overcome velocity strengthening cannot result in a total stress drop. In the area of the shallow surge, the upper plate is more compliant than the lower plate. This provides the possibility that the bimaterial effect could overcome velocity strengthening by reducing the normal stress and lead to the rupture propagating as a wrinkle pulse. This would result in total stress drop and weak short-period radiation. The initiation of such a wrinkle pulse requires a very strong nucleation pulse and thus can be triggered only by a very large rupture at depth. This conjecture appears to be in accord with all the relevant facts regarding the shallow surge. It is partially validated by the modeling of Kozdon and Dunham (2013), which implicitly includes the bimaterial effect. Their model that best fits the data employs a velocity-strengthening region that extends a distance $W$ of only $30 \mathrm{~km}$ from the trench. The onset of the surge, however, was at least $60 \mathrm{~km}$ from the trench and the trenchward limit of ordinary earthquakes is about $75 \mathrm{~km}$ from the trench, which implies that $W$ should lie between those limits. Their model with $W=60 \mathrm{~km}$ shows slip suppressed in the velocity-strengthening region and not extending to the trench. Nevertheless, their work shows that the concept is most likely correct.

Lay et al. (2012) showed that shallow-slip surges, depleted in the high-frequency radiation, also occurred in the $2004 M_{\mathrm{w}} 9.2$ Sumatra-Andaman earthquake and in the 2010 $M_{\mathrm{w}} 8.8$ Maule, Chile, earthquake. It therefore seems, in accordance with the proposed hypothesis, that such behavior is common to many of the greatest subduction zone earthquakes.

\section{Data and Resources}

All data in this paper are from cited published sources.

\section{Acknowledgments}

I thank Heather Savage for discussions at various stages of this work. Two anonymous reviewers made useful comments that led to improvements in the paper.

\section{References}

Andrews, D. J., and Y. Ben-Zion (1997). Wrinkle-like slip pulse on a fault between different materials, J. Geophys. Res. 102, no. B1, 553-571. 
Andrews, D. J., and R. A. Harris (2005). The wrinkle-like slip pulse is not important in earthquake dynamics, Geophys. Res. Lett. 32, no. 23, doi: 10.1029/2005GL023996.

Andrews, D. J., and R. A. Harris (2006). Reply to "Comment on 'The wrinklelike slip pulse is not important in earthquake dynamics' by Y. Ben-Zion", Geophys. Res. Lett. 33, no. 6, doi: 10.1029/2006GL025743.

Anooshehpoor, A., and J. N. Brune (1999). Wrinkle-like Weertman pulse at the interface between two blocks of foam rubber with different velocities, Geophys. Res. Lett. 26, no. 13, 2025-2028.

Ben-Zion, Y. (2006). Comment on "The wrinkle-like slip pulse is not important in earthquake dynamics" by D. J. Andrews and R. A. Harris, Geophys. Res. Lett. 33, no. 6, doi: 10.1029/2005GL025372.

Chester, F. M., C. Rowe, K. Ujiie, J. Kirkpatrick, C. Regalla, F. Remitti, J. C. Moore, V. Toy, M. Wolfson-Schwer, S. Bose, J. Kameda, J. J. Mori, E. E. Brodsky, N. Eguchi, and S. Toczko (2013). Structure and composition of the plate-boundary slip zone for the 2011 Tohoku-Oki earthquake, Science 342, no. 6163, 1208-1211.

Cubas, N., J. P. Avouac, Y. M. Leroy, and A. Pons (2013). Low friction along the high slip patch of the $2011 M_{\mathrm{w}} 9.0$ Tohoku-Oki earthquake required from the wedge structure and extensional splay faults, Geophys. Res. Lett. 40, no. 16, 4231-4237.

Di Toro, G., T. Hirose, S. Nielsen, G. Pennacchioni, and T. Shimamoto (2006). Natural and experimental evidence of melt lubrication of faults during earthquakes, Science 311, 647-649.

Faulkner, D. R., T. M. Mitchell, J. Behnsen, T. Hirose, and T. Shimamoto (2011). Stuck in the mud? Earthquake nucleation and propagation through accretionary forearcs, Geophys. Res. Lett. 38, doi:10.1029/ 2011 GL048552.

Fujiwara, T., S. Kodaira, T. No, Y. Kaiho, N. Takahashi, and Y. Kaneda (2011). The 2011 Tohoku-Oki earthquake: Displacement reaching the trench axis, Science 334, no. 6060, 1240-1240.

Fulton, P. M., E. E. Brodsky, Y. Kano, J. Mori, F. Chester, T. Ishikawa, R. N. Harris, W. Lin, N. Eguchi, and S. Toczko (2013). Low coseismic friction on the Tohoku-Oki fault determined from temperature measurements, Science 342, no. 6163, 1214-1217.

Harris, R. A., and S. M. Day (1997). Effects of a low-velocity zone on a dynamic rupture, Bull. Seismol. Soc. Am. 87, no. 5, 1267-1280

Harris, R. A., and S. M. Day (2005). Material contrast does not predict earthquake rupture propagation direction, Geophys. Res. Lett. 32, no. 23, doi: 10.1029/2005GL023941.

Hashimoto, C., A. Noda, T. Sagiya, and M. Matsu'ura (2009). Interplate seismogenic zones along the Kuril-Japan trench inferred from GPS data inversion, Nature Geosci. 2, 141-144.

Hyndman, R. D., and K. Wang (1993). Thermal constraints on the zone of major thrust earthquake failure: The Cascadia subduction zone, J. Geophys. Res. 98, 2039-2060.

Ide, S., A. Baltay, and G. C. Beroza (2011). Shallow dynamic overshoot and energetic deep rupture in the $2011 M_{\mathrm{w}} 9.0$ Tohoku-Oki earthquake, Science 332, no. 6036, 1426-1429.

Ito, A., G. Fujie, S. Miura, S. Kodaira, Y. Kaneda, and R. Hino (2005). Bending of the subducting oceanic plate and its implication for rupture propagation of large interplate earthquakes off Miyagi, Japan, in the Japan Trench subduction zone, Geophys. Res. Lett. 32, no. 5, doi: 10.1029/2004GL022307.

Kodaira, S., T. No, Y. Nakamura, T. Fujiwara, Y. Kaiho, S. Miura, N. Takahashi, Y. Kaneda, and A. Taira (2012). Coseismic fault rupture at the trench axis during the 2011 Tohoku-Oki earthquake, Nature Geosci. 5, no. 9, 646-650.

Koper, K. D., A. R. Hutko, T. Lay, C. J. Ammon, and H. Kanamori (2011) Frequency-dependent rupture process of the $2011 M_{\mathrm{w}} 9.0$ Tohoku earthquake: Comparison of short-period $\mathrm{P}$ wave backprojection images and broadband seismic rupture models, Earth Planets Space 63, 599-602.

Kozdon, J. E., and E. M. Dunham (2013). Rupture to the trench: Dynamic rupture simulations of the 11 March 2011 Tohoku earthquake, Bull. Seismol. Soc. Am. 103, 1275-1289.
Lay, T., H. Kanamori, C. J. Ammon, K. D. Koper, A. R. Hutko, L. Ye, H. Yue, and T. M. Rushing (2012). Depth-varying rupture properties of subduction zone megathrust faults, J. Geophys. Res. 117, no. B04311, doi: 10.1029/2011JB009133.

Lin, W., M. Conin, J. C. Moore, F. M. Chester, Y. Nakamura, J. J. Mori, L. Anderson, E. E. Brodsky, and N. Eguchi (2013). Stress state in the largest displacement area of the 2011 Tohoku-Oki earthquake, Science 339, 687-690.

Loveless, J. P., and B. J. Meade (2010). Geodetic imaging of plate motions, slip rates, and partitioning of deformation in Japan, J. Geophys. Res. 115, doi: 10.1029/2008JB006248.

Lykotrafitis, G., and A. J. Rosakis (2006). Dynamic sliding of frictionally held bimaterial interfaces subjected to impact shear loading, Proc. Math. Phys. Eng. Sci. 462, no. 2074, 2997-3026.

Ma, K. F., E. E. Brodsky, J. Mori, C. Ji, T. R. A. Song, and H. Kanamori (2003). Evidence for fault lubrication during the 1999 Chi-Chi, Taiwan, earthquake ( $M_{\mathrm{w}}$ 7.6), Geophys. Res. Lett. 30, no. 5, doi: 10.1029/2002GL015380.

Minoura, K., F. Imamura, D. Sugawara, Y. Kono, and T. Isashita (2001). The 869 Jogan Tsunami deposit and recurrence interval of large-scale tsunami on the Pacific coast of Japan, J. Nat. Disast. Sci. 23, 83-88.

Noda, H., and N. Lapusta (2013). Stable creeping fault segments can become destructive as a result of dynamic weakening, Nature 493, no. 7433, $518-521$.

Obana, K., S. Kodaira, M. Shinohara, R. Hino, K. Uehira, H. Shiobara, K. Nakahigashi, T. Yamada, H. Sugioka, A. Ito, Y. Nakamura, S. Miura, T. No, and N. Takahashi (2013). Aftershocks near the updip end of the 2011 Tohoku-Oki earthquake, Earth Planet. Sci. Lett. 382, 111-116.

Rabinowitz, H. S., H. M. Savage, P. J. Polissar, T. Plank, C. D. Rowe, and J. D. Kirkpatrick (2013). Detecting the frictional temperature rise during the 2011 Tohoku earthquake using the thermal maturity of biomarkers, AGU Fall Meeting Abstracts 1, 07.

Saffer, D. M., and C. Marone (2003). Comparison of smectite- and illite-rich gouge frictional properties: Application to the updip limit of the seismogenic zone along subduction megathrusts, Earth Planet. Sci. Lett. 215, nos. 1/2, 219-235.

Scholz, C. H. (1998). Earthquakes and friction laws, Nature 391, no. 6662 , $37-42$.

Scholz, C. H., and J. Campos (2012). The seismic coupling of subduction zones revisited, J. Geophys. Res. 117, no. B05310, doi: 10.1029/ 2011JB009003.

Simons, M., S. E. Minson, A. Sladen, F. Ortega, J. Jiang, S. E. Owen, L. Meng, J.-P. Ampuero, S. Wei, and R. Chu et al. (2011). The 2011 magnitude 9.0 Tohoku-Oki earthquake: Mosaicking the megathrust from seconds to centuries, Science 332, no. 6036, 1421-1425.

Tajima, F., J. Mori, and B. L. N. Kennett (2013). A review of the 2011 Tohoku-Oki earthquake $\left(M_{\mathrm{w}}\right.$ 9.0): Large-scale rupture across heterogeneous plate coupling, Tectonophysics 586, 15-34

Tsuji, T., K. Kawamura, T. Kanamatsu, T. Kasaya, K. Fujikura, Y. Ito, T. Tsuru, and M. Kinoshita (2013). Extension of continental crust by anaelastic deformation during the 2011 Tohoku-Oki earthquake: The role of extensional faulting in generation of a great tsunami, Earth Planet. Sci. Lett. 362, 44-58.

Weertman, J. (1980). Unstable slippage across a fault that separates elastic media of different elastic constants, J. Geophys. Res. 85, 1455-1461.

Yamamoto, Y., R. Hino, and M. Shinohara (2011). Mantle wedge structure in the Miyage Prefecture forearc region, central northeastern Japan arc, and its relation to corner-flow pattern and interplate coupling, J. Geophys. Res. 116, no. B10310, doi: 10.1029/2011JB008470.

Lamont-Doherty Earth Observatory Palisades, New York 10964

Manuscript received 9 May 2014; Published Online 19 August 2014 